\title{
Interaction of wildlife research and forest management: The need for maturation of science and policy
}

\author{
by Thomas A. Hanley
}

Foresters and wildlife biologists face new challenges and new expectations from society. They are expected to provide an increasingly wide variety of goods and services from ecosystems at the same time that natural systems are under increasing pressure from both environmental and economic forces. The challenge is very formidable and requires a significant increase in the efficiency of both research and management. It is particularly important that research and management work in concert to provide a scientific basis for management. The communication gap between research and management, however, is a serious impediment. It is primarily one of false expectations, and it needs to be reduced. A major gain in that reduction can be made by recognizing the distinctly different roles of research and management. The role of research is to improve our understanding of our world. The role of management is to incorporate that understanding into policy and action. There is a fundamental difference between the technical knowledge that is science and the technical tools that are required to apply science to management. The technical tools are part of management and often must go considerably beyond the limits of scientific rigour. Research is needed to advance theory. Greater technical expertise within management is needed for management to benefit most fully from science. A shift in expectations from research will help make research more productive in advancing science and will free management from its dependency on research for technical tools.
Les forestiers et les biologists de la faune font face à de nouveaux défis ainsi qu'à de nouvelles attentes de la part de la société. On s'attend à ce qu'ils soient en mesure de fournir une variété sans cesse grandissante de biens et de services tirés d'écosystèmes alors qu'au même moment les systèmes naturels sont soumis à des pressions de plus en plus fortes exercées à la fois par des forces environnementales et économiques. Le défi est de taille et requiert une augmentation significative de l'efficacité tant au niveau de la recherche que de la gestion. Il est de primordial que la recherche et la gestion collaborent ensemble pour mettre en place une base scientifique destinée à la gestion. Le manque de communication entre la recherche et la gestion constitue toutefois un obstacle majeur. Il est principalement constitué de fausses attentes, et se doit d'être résolu. Une étape importante pour combler ce vide peut être effectuée en reconnaissant les rôles clairement différents de la recherche et de la gestion. Le but de la recherche est d'améliorer notre compréhension de notre monde. Le but de la gestion forestière est d'incorporer cette compréhension sous forme de politiques et d'actions. Il existe une différence fondamentale entre la connaissance technique constituée à partir de la science et les outils techniques qui sont requis pour appliquer la science à la gestion. Les outils techniques font partie de la gestion et doivent être utilisés souvent au delà des limites que permet la rigueur scientifique. La recherche est requise pour faire avancer la théorie. Une expertise technique plus importante au niveau de la gestion est requise pour que ce domaine puisse bénéficier pleinement de la science. Un changement dans les attentes placées dans la science aidera à rendre la recherche plus productive sur le chemin du progrès scientifique et libérera la gestion de sa dépendance liée à la recherche d'outils techniques.

\section{Introduction}

The last decade of the 20th Century is one of unprecedented rates of social, economic, and ecological change throughout the world. Both the fields of forestry and wildlife biology are caught-up in that change, and both have new and increasingly important problems to solve through research and management. Society is demanding a much broader service of forestry than one concentrated on wood fibre production: the role of forests in carbon, nutrient, and hydrologic cycles, their buffering capacities for pollutants, and their importance as habitat and reservoirs of biodiversity have suddenly gained global political significance. Wildlife biology, too, is faced with global concern about biodiversity, habitat loss, endangered species, and ecological as well as social values of wild plants and animals. The interaction between wildlife biology and forestry is particularly interesting and illustrates the nature of change within both disciplines.

Recent analyses of emerging research priorities relevant to forest wildlife are many and varied (Soulé and Kohm 1989, National Research Council 1990, Kininmonth and Tarlton 1991, Lubchenco et al. 1991, Huntley et al. 1991, Dooge et al.

United States Forest Service, Pacific Northwest Research Station, P.O. Box 20909, Juneau, AK, 99802-0909 USA.
1992). What they have in common, however, is (1) a recognition of the ecological importance of wild plants and animals extending beyond their value as consumptive resources, (2) the need for greater understanding of their ecology, particularly in respect to ecosystem function, (3) an emphasis on the importance of maintaining global biodiversity and sustainable production, and (4) alarm at the accelerating rates of global change, the irreversible losses of habitat and genetic resources, and the need for concerted effort between both basic and applied research and management. The needs and opportunities for forest wildlife research are growing, but they also are changing.

The research budget of the United States Forest Service, for example, provides a good illustration of the changing research climate: The total Forest Service research budget (in constant dollars) decreased slightly or remained about the same during the period 1980-1990; but the portion for wildlife, range, and fish habitat research increased by more than 30 percent, especially during the last four years (Fig. 1). Also significantly, however, the increased funding was largely for high priority species, especially the northern spotted owl (Strix occidentalis) and salmonid fishes protected by the Endangered Species Act and affected by clearcut logging of old-growth forests in the Pacific Northwest. The increase was not for wildlife habitat generally or for game species in particular. The trends continued in 1991-1993 (but the budget tracking system changed and so 


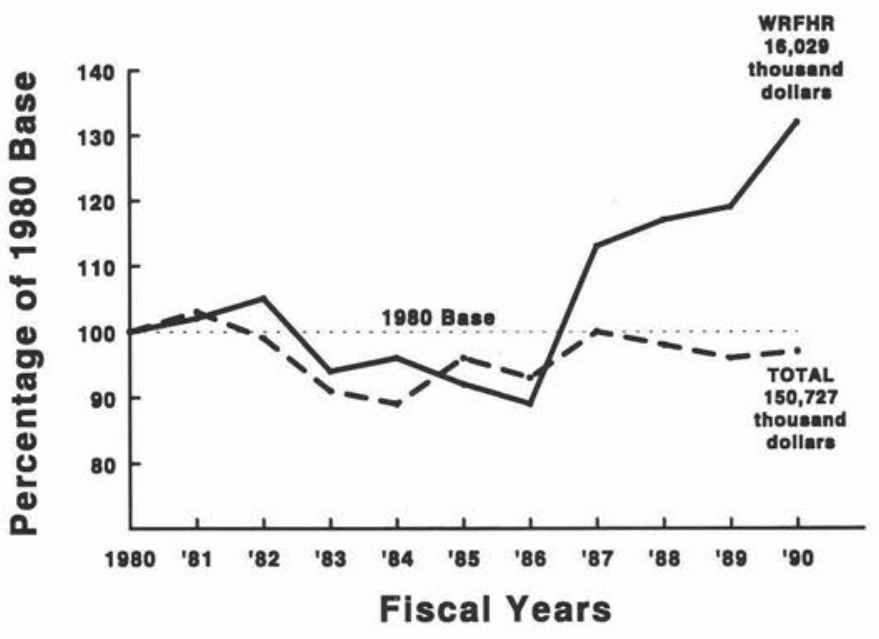

Figure 1. Relative changes in annual appropriations for Wildlife, Range, and Fish Habitat Research (WRFHR) and total U.S. Forest Service Research (TOTAL), 1980-1990, expressed as a percentage of 1980 amounts (adjusted for inflation, to constant 1991 dollars). Source: R.C. Szaro, U.S. Forest Service, Washington, DC.

could not be included in Fig. 1). The availability of money for wildlife research increased greatly since 1986 at the expense of other forest research disciplines, but the increase was in response to emergency situations unrelated to game management. The future in forest wildlife biology lies in landscape planning, community analyses, endangered species, and biodiversity, not in game management. Those trends are worldwide, albeit they are at different stages in different countries.

Both the opportunities and responsibilities of wildlife biologists have increased as the global environment, forestry, and wildlife biology have gained importance among political leaders and ecologists. But the competitive environment of wildlife research is also changing as many basic researchers move toward applied problems and applied problems shift toward more basic ecological questions. Sources for funding of basic research also have tightened as the global economy has tightened, and scientists are increasingly required to justify the utility of their research (Brown 1992). Distinctions between basic and applied research are diminishing (Wiens 1992).

Forestry, ecology, and especially wildlife biology are young sciences, but very much is being expected of them now. Increased responsibilities and competition mean that both research and management need to increase their efficiency. (I use the term management in this paper to refer to the management of natural resources, in this case forest or wildlife management, not the administrative management of human or financial resources; Fig. 2). Society is expecting and demanding more service for less money - a rapid maturation of both science and policy.

One way that both science and policy can improve significantly is through better understanding of the separate yet interdependent roles of research and management in the scientific management of natural resources. The communication gap between research and management is a common, worldwide phenomenon, a major source of inefficiency in both endeavors, and one that can be reduced significantly by an understanding of its nature. I contend that fundamental misunderstanding

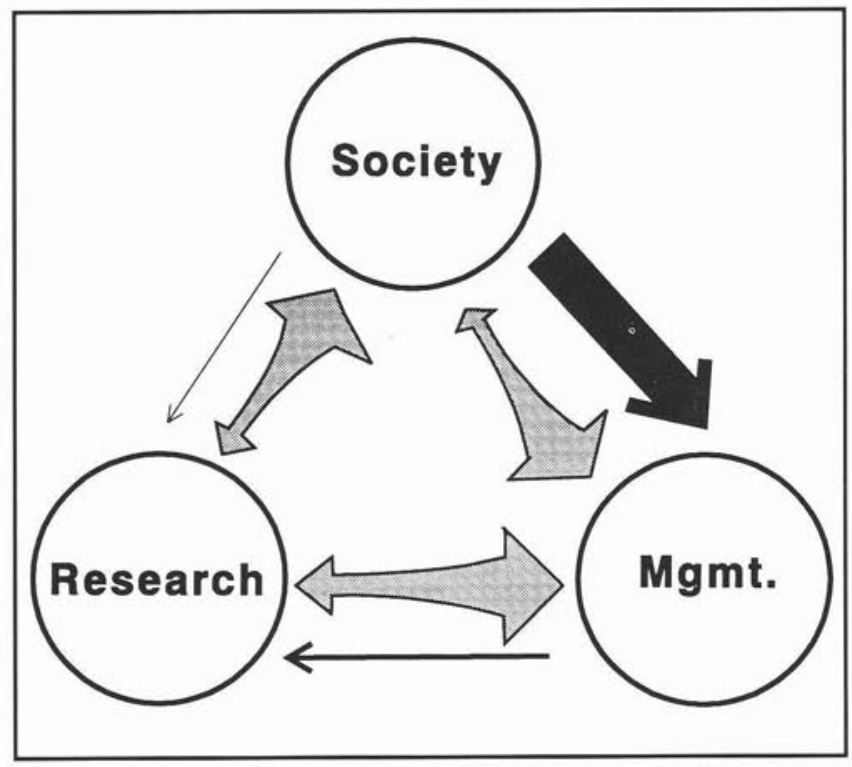

Figure 2. Interactions between society, research, and management of natural resources. The three are linked by funding and information flows (funding indicated by solid arrows, widths indicative of relative amounts; information indicated by stippled arrows). Additionally, management provides society with goods and services. Significant communication gaps exist in all of the information flows. Those to society are primarily the role of education, which in turn ultimately determines the quality of the information flows from society. Although the interactions with society are important, the communication gap between research and management is the focus of my analysis. That information flow is the basis for the "scientific management" of natural resources.

of expectations between research and management has retarded the maturation of both science and policy in natural resource management. The case of wildlife research and forest management is a classic example.

\section{The Gap between Research and Management}

A common perspective within the resource management community is that research is often too narrow, too basic, or simply irrelevant to managers' needs. Researchers are often seen as motivated by self-aggrandizement, rewarded within a system that is insensitive to the practical, real-life problems of management, and simply out of touch with reality and the time and money constraints that managers must operate within daily. Research problem selection and approach often seem esoteric and of extremely limited applicability to management problems, while major research needs are frequently avoided altogether.

A common perspective within the research community, on the other hand, is that managers choose not to use most of the research done for their benefit, that they want too overly simplified, cookbook solutions to complex problems, and that research is chronically underfunded relative to management's expectations. Researchers frequently are frustrated by feeling the need to be useful at the expense of scientific rigour.

The combination of those two perspectives has resulted in much inefficient use of limited research money: research that was not good science because it was too applied and yet never found application either. The situation exists in both forestry and wildlife biology. It exists in government, private industry, and academia. 
The solutions most frequently suggested are that research and management should work more closely to bridge the gap between research and management, that management should ask the questions that research addresses, or that research should approach management as an experiment itself (e.g., Macnab 1983, Nudds and Morrison 1991, Sinclair 1991, Murphy and Noon 1991). The central idea is that applied research should be more responsive to management, while management should be more open to applied research, and that both can benefit from basic research peripherally (Fig. 3a).

An alternative viewpoint (Fig. 3b), however, suggests a different solution: that basic and applied researchers should work more closely in developing a scientific knowledge of key ecological processes, while managers benefit from advances in science by revising their analytical tools accordingly. This alternative viewpoint assumes that research and management are fundamentally and qualitatively different kinds of intellectual endeavours: management needs to be based on scientific knowledge, but a critical requirement of science is to ask questions that can be answered. When researchers address questions that are too big, that cannot be answered unambiguously, their short-cuts to practical utility really lead them nowhere. Real gains in scientific understanding of processes and mechanisms that determine system response to management are of very real and significant utility. But they often require a longterm or interdisciplinary research program of interrelated studies.

I suggest that the first step toward reducing the communication gap between research and management is recognition of the fundamental difference between the roles of research and management in science and policy. The second step is recog-

\section{A)}

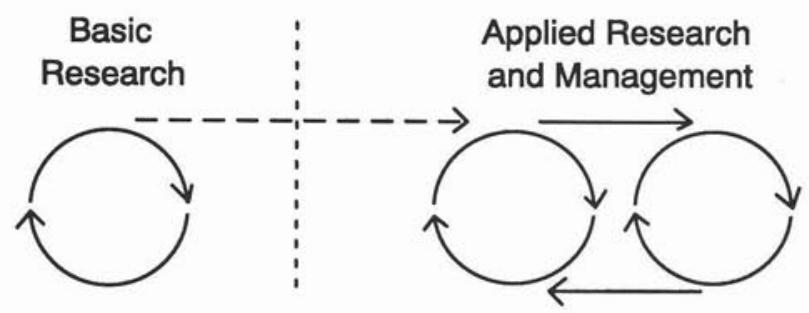

B)

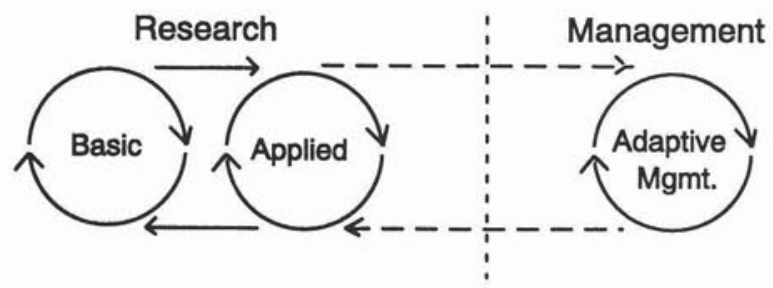

Figure 3. Paradigms of relations between research and management in forestry and wildlife management. Solid arrows indicate close linkages; broken arrows and vertical lines indicate weaker linkages. (A) The conventional viewpoint ties applied research and management most closely together, both benefiting peripherally from basic research. (B) An alternative viewpoint that ties basic and applied research most closely together, with management benefiting from and contributing to the combination. The difference in viewpoints results in fundamentally different expectations between management and applied research. nition of their interdependence. The difference in viewpoints (Fig. 3a vs. 3b) is not trivial; it determines the expectations between research and management and, consequently, the very nature of the interaction.

\section{The Role of Research}

Science is a philosophy of how we view our world. The role of research is to improve that philosophy, to change and improve our view of how nature works, both qualitatively and quantitatively. The link to management is through sensitivity to management's needs in the process of problem selection. The chief difference between basic and applied research is that problem selection is driven by management needs (application) in the latter. Both basic and applied research require the same standards of rigour, and they approach many of the same theoretical problems, differing only in their reasons for problem selection. The knowledge must be sound in both cases. That is what constitutes science, and that is what makes for a scientific basis for management.

The science of ecology is only about a century old, and wildlife biology, as a science, is only about half as old as that (Klein 1990). Living systems are extremely complex, and natural environments pose many difficulties for experimentation. It is not surprising, therefore, that both ecology and wildlife biology are still relatively immature, with weak, ambiguous theory and difficulty in formulating and testing serious hypotheses that have strong explanatory power (Loehle 1987). Descriptive studies have constituted most of the research in both fields until only recently. Explanations and theory have largely been inferential and, consequently, subject to the problem of multiple possible causation. As ecology develops toward a more mature, mechanistic science, however, its explanatory and predictive powers will increase (Wiens 1992). The same is true, of course, for wildlife biology.

Research of mechanistic processes is vitally important to wildlife biology. Understanding underlying mechanisms is the basis for predictive and explanatory theory, that ultimately has very strong practical utility. Without such theory, every management problem is a new and unique case. With weak theory, every case is subject to multiple interpretations with little understanding. However, research of mechanistic processes is frequently seen by management as basic research and not applicable to their problems, especially if studies do not have direct management implications. Descriptive studies concluding with speculative inferences tend to be favoured, especially when the inferences have direct application. The consequence is retardation rather than advancement of science (Romesburg 1981).

The hypothetico-deductive method of science is widely considered the most efficient process for advancing theory (Popper 1959, Platt 1964) and is a cornerstone of modern, western science. It is a method that is difficult to apply in ecology, though, where difficulties caused by such factors as randomness, complexity, and unobserved or uncontrollable variables are common (Loehle 1987). Such difficulties increase with scale and are especially great when the hypothetico-deductive method is applied to the analysis of management-as-an-experiment. Tests of cause-and-effect relations are not possible when the effects of separate factors are unknown and cannot be isolated. It is important to define predictions in ways that can be tested unambiguously. Scientific progress consequently tends to be favoured by a reductionist approach that addresses 
questions that, individually, are much more narrow than those asked by management. Collectively, however, the answers and resulting theory are much broader than the case-by-case management questions.

Research that advances theory applicable to management is ultimately the most useful research for management. Distinction between basic and applied research in such cases is nonsense. Distinction between ambiguous and unambiguous studies, on the other hand, is always important.

\section{The Role of Management}

Modern forestry and wildlife management are based on philosophies embodying the concept of scientific management. The introduction of science to wildlife management has been credited to an American forester, Aldo Leopold (1933). Leopold's ideas were formulated from a combination of his experiences with American and European forestry, European (especially German) game management, and the newly developing science of ecology, especially population ecology. It was the application of ecological theory and the scientific method that changed wildlife management from a subjective art based largely on tradition to a technical, scientific profession (Klein 1990). Theory and research are an integral part of wildlife management today.

Wildlife management in the 1940s through '60s continued its emphasis almost exclusively on game species and population ecology. The environmental movement within the politics of the 1970 s began to demand more from wildlife biologists than such a heavy emphasis on game management. Nongame species became increasingly important as well as technical evaluation of habitat and analysis of the environmental impact of economic development. The working environment for wildlife biologists in the 1990s has become one of much technical, political, and even legal controversy (Murphy and Noon 1991). The scientific basis for wildlife management (Fig. 2) is under intense scrutiny. Forestry has been especially shaken in the political process and is currently undergoing a philosophical reevaluation concerning its effects on wildlife habitat. Both wildlife management and forest management need a strong scientific basis now more than ever. Managers look to research for that need. But is it a need that research can fully meet?

Research is technical, quantitative, and supposed to be objective. Management increasingly needs technical, quantitative, and objective analyses and tools for decision making. But management is not science. It is broader than science, and it must accommodate societal desires within a political arena, not a scientific one. It also must formulate policy and make decisions on the basis of what is currently known; it cannot wait for further development of scientific knowledge. Furthermore, much of the technological way of thinking that is useful in research is inadequate for management: a reductionist, mechanistic approach is too narrow to encompass the multiplicity of factors that must be dealt with simultaneously in management (Miller 1985). It is important to recognize that management cannot afford the confines of the rigours of science, nor are they appropriate.

Habitat evaluation models, for example, are an important analytical tool for many wildlife biologists working in forest management. The models are usually technically complex, combining many separate physical and biological factors into one quantitative index of habitat quality for a given species on a given landscape (e.g., U.S. Fish and Wildlife Service 1981, Verner

et al. 1986). The index would ideally be some measure of potential population density and productive capacity of the habitat. Such a calculation would be extremely difficult for a scientifically rigourous model. The many cause-and-effect relations are too complex. Even if all the cause-and-effect relations were known and quantified, the cumulative error from the many multiplicative calculations would grow enormously. The habitat evaluation models, therefore, must rely on gross oversimplifications of processes and reality, with many relations that are untestable scientifically (Fig. 4).

The relation between habitat quality and elevation (Fig. 4a), for example, is a very important consideration for mountainous terrain in northern environments. Yet it is impossible to test directly: What is the response variable that one should measure? How can the elevation factor be isolated from all the other factors that also vary on a natural landscape? The causal relations involve the energetic cost of locomotion in snow (Fig. 4b), for one, which can be tested and quantified through research. But energy expenditure for locomotion is only part of the energy balance equation; food quality and intake are at least equally important and more complicated than energy expenditure. The elevation factor alone, from a research standpoint, is complex. Yet it is only one of many important factors that managers must consider. Similarly, the needs to incorporate landscape analyses into forest management go far beyond the current limits of landscape ecology as a science and inevitably will require oversimplifications as that science develops also.

A major benefit of models built on oversimplified relations is that they are practical and understandable. The analytical assumptions are identified explicitly and quantitatively. A major disadvantage is that the models are not testable. Predictions might be correct sometimes but for the wrong reasons. Incorrect predictions cannot be traced to their source of error. The models sacrifice scientific rigour (unambiguous testability) for necessary pragmatic utility.

A.

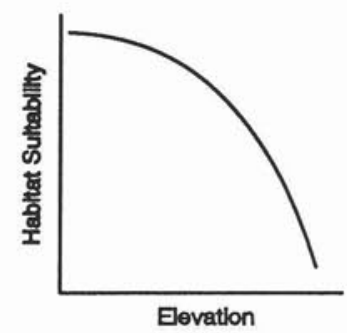

Figure 4. Modelling ecological effects of snow within a larger model of habitat analysis. The needs of management and research differ greatly. (A) The relation between snow accumulation and elevation has important effects on winter habitat suitability for wildlife in northern climates. Models for management analyses must simplify the relation in a way that is intuitively understandable and practical in application. The relation, however, is untestable. It has important management applications but is of very little value for research. (B) An important and testable relation for research involves the energetic cost of locomotion in snow in relation to the depth to which an animal sinks. It is only one small part of the energy balance equation, however, and is of very limited utility in direct application to management. 
Just as science is a simplified abstraction of nature, so scientific management of natural resources is a simplifed abstraction of science. But even though management models and other analytical tools may need to go beyond the limits of scientific rigour, they still must be consistent with our understanding of nature based on science.

Scientific management requires a thorough understanding of science and a high degree of technical creativity for developing analytical tools. Too frequently, however, management looks to research for those tools. What is needed is a new and more technically oriented breed of professional within management: a scientific staff responsible for translating science into application. Such translation is not research. To expect it from researchers results in a reduction in either the quantity or quality of research or both.

A scientific staff within management also is needed for long-term monitoring of the results of management, which is an essential part of "adaptive management" (Holling 1978, Walters and Holling 1990). Adaptive management is the process of monitoring results, comparing them with stated objectives, and modifying management to better attain the objectives. It has received much verbal support but has been very slow to be implemented, because monitoring has seldom been incorporated into management, a clear example of a young stage in policy.

Sound and efficient monitoring of the effects of management is usually a highly technical and difficult problem, yet it is critically important for knowing whether management is achieving its objectives. Monitoring is frequently mentioned as a research need in forest and wildlife management. The technical difficulties, however, do not make it research. Research already has provided methods for data collection and the statistical theory for data analysis. Further research is needed in both those areas, but what management needs first is technical expertise to apply what already is known and a long-term commitment to monitoring and adaptive management.

Greater technical expertise within management is an opportunity to benefit from science in a way that uses theory as a base and expands upon it to meet current requirements. Science provides only the theoretical underpinnings for management. To expect more from science than that is to expect too much.

\section{Interaction between Research and Management}

Research and management have much to be gained from each other, and scientific management of forests and wildlife depends on the interaction of science and policy. Three major steps toward greater maturity of policy are (1) recognition of the role of research in advancing science and the role of theory in management, (2) acceptance of responsibility within management for translating science to application (management models, analytical tools, monitoring procedures, etc.), and (3) commitment to long-term monitoring programs and adaptive management policies. Policy is currently at a young stage in all three of those areas.

Three major steps toward greater maturity of forestry and wildlife science are (1) recognition of the need for strong, mechanistic theory with important, testable hypotheses, (2) requirement of high standards of scientific rigour and unambiguous experiments, and (3) commitment to practical utility through problem selection based on management's needs for predictive theory. Forestry and wildlife sciences, too, are currently at a young stage in all three of those areas.

The reasons for the current lack of maturity are partly historical: forestry, wildlife biology, and ecology are young sciences; the needs for scientific analyses and highly technical solutions have increased at an exponential rate, especially within the past two decades; and the technical responsibilities have traditionally fallen to research. Furthermore, managers with little experience in research and inadequately educated in the philosophy of science have traditionally controlled the major purse strings for research funding within both forestry and wildlife biology (Fig. 2). The consequent blurred distinction between the separate roles of research and management has fostered confusion, inefficiency, and much dissatisfaction on both sides of the communication gap. But it doesn't have to be that way.

The process of research problem selection is of primary concern to both research and management. The problem must have important application to management and also be conducive to developing predictive theory. Researchers frequently find themselves torn between taking on too large and too ambiguous a problem (in the effort to be applicable to management) and too narrow, too specialized a problem (in the effort to do rigorous science). The former has been encouraged by funding from management, and the latter has been encouraged by funding from basic science sources. The most productive and useful research, however, is between those extremes.

Descriptive, exploratory studies and narrow, independent studies can be very valuable for generating and developing important ideas. We certainly need both of those approaches. But we also need a third: I suggest that the most productive middle ground is most likely to be found in long-term (e.g., 10 years) research programs of coordinated, interrelated studies. Answers to big questions seldom come from one or two studies. Rather, they require a coordinated attack from many different angles and increasingly require interdisciplinary coordination, too. Effective programs require a commitment of research to a particular problem and must be selected with long-term objectives in mind. That is where the philosophical approach and understanding of science by administrators is particularly important. Similarly, research also must be proactive, not just reactive, to management's needs. Science must lead the way for policy. That requires foresight and independence from the overriding importance of immediate political concerns. All three of the above (long-term, coordinated programs; interdisciplinary research; and independence from immediate exigencies) are uncommon in forest and wildlife research today.

There is worldwide concern that the communication gap between research and management is a substantial problem resulting in much inefficiency. The viewpoint, approach, and solution that I have offered here are different from the more common ones that emphasize greater immediate, practical application from research (Fig. 3). On the contrary, I believe the short-term, utilitarian emphasis is fine within management but is self-defeating within research. The distinction is critically important. Management needs sound scientific theory just as much as it needs utilitarian analytical tools, and it can't afford to wait for basic research alone to develop the necessary theory. Research is vital for scientific management because science is theory. Understanding the different, separate, and interrelated roles of research and management should reduce false expectations, facilitate communication, and improve the quality of both research and management. 


\section{Acknowledgements}

I thank I.M. Korhonen for challenging me to write this, I.D.

Thompson for the opportunity to present it at the XXI IUGB Congress, and M.D. Bryant, F.H. Everest, M.D. Kirchhoff, and D.R. Klein for their helpful reviews of an earlier draft of the manuscript.

\section{References}

Brown, G.E. 1992. Rational science, irrational reality: A Congressional perspective on basic research and society. Science 258: 200-201.

Dooge, J.C.I., G.T. Goodman, J.W.M. la Rivière, J. MartonLefèvre, T.O. O'Riordan and F. Paderie (eds.). 1992. An agenda of science for environment and development into the 21st Century (based on a conference held in Vienna, Austria in November 1991). Cambridge University Press, Cambridge, UK. 331 pp.

Holling, C.S. (ed.). 1978. Adaptive environmental management. John Wiley and Sons, Chichester, UK. 377 pp.

Huntley, B.J., E. Ezcurra, E.R. Fuentes, K. Fujii, P.J. Grubb, W. Haber, J.R.E. Harger, M.M. Holland, S.A. Levin, J. Lubchenco, H.A. Mooney, V. Neronov, I. Noble, H.R. Pulliam, P.S. Ramakrishnan, P.G. Risser, O. Sala, J. Sarukhan and W.G. Sombroek. 1991. A sustainable biosphere: the global imperative. Ecology International 20: 5-14.

Kininmonth, J.A. and G.L. Tarlton (eds.). 1992. Forestry research management initiatives for the 1990s: Proceedings of the IUFRO subject groups S6.06 and S6.08 conference, Forest Research Institute, Rotorua, New Zealand, 1991. 296 pp.

Klein, D.R. 1990. The evolving role of research in management of wildlife populations. pp. 9-13. In S. Myrberget (ed.). Trans. 19th Congress IUGB, Trondheim, Norway, 1989.

Leopold, A. 1933. Game management. Charles Scribner's Sons, New York, NY, USA 481 pp.

Loehle, C. 1987. Hypothesis testing in ecology: psychological aspects and the importance of theory maturation. Quarterly Review of Biology 62: 397-409.
Lubchenco, J., A.M. Olson, L.B. Brubaker, S.R. Carpenter, M.M. Holland, S.P. Hubbell, S.A. Levin, J.A. MacMahon, P.A. Matson, J.M. Melillo, H.A. Mooney, C.H. Peterson, H.R. Pulliam, L.A. Real, P.J. Regal and P.G. Risser. 1991. The sustainable biosphere initiative: an ecological research agenda. Ecology 72: 371-412. Macnab, J. 1983. Wildlife management as scientific experimentation. Wildlife Society Bulletin 11: 397-401.

Miller, A. 1985. Technological thinking: its impact on environmental management. Environmental Management 9: 179-190.

Murphy, D.D. and B.D. Noon. 1991. Coping with uncertainty in wildlife biology. Journal of Wildlife Management 55: 773-782.

National Research Council. 1990. Forestry research: a mandate for change. National Academy Press, Washington, DC, USA. 83 pp.

Nudds, T.D. and M.L. Morrison. 1991. Ten years after "Reliable Knowledge": are we gaining? Journal of Wildlife Management 55: 757-760.

Platt, J.R. 1964. Strong inference. Science 146: 347-353.

Popper, K.R. 1959. The logic of scientific discovery. Hutchinson, London, U.K. 480 pp.

Romesburg, H.C. 1981. Wildlife science: gaining reliable knowledge. Journal of Wildlife Management 45: 293-313.

Sinclair, A.R.E. 1991. Science and the practice of wildlife management. Journal of Wildlife Management 55: 767-773.

Soulé, M.E. and K.A. Kohm. 1989. Research priorities for conservation biology. Island Press, Washington, DC, USA. 95 p.

U.S. Fish and Wildlife Service. 1981. Standards for the development of habitat suitability index models. Ecological services manual 103. U.S. Fish and Wildlife Service, Washington, DC, USA.

Verner, J., M.L. Morrison and C.J. Ralph (eds.). 1986. Wildlife 2000: Modeling wildlife-habitat relationships of terrestrial vertebrates. University of Wisconsin Press, Madison, Wisconsin, USA. 470 p. Walters, C.J. and C.S. Holling. 1990. Large-scale management experiments and learning by doing. Ecology 71: 2060-2068.

Wiens, J.A. 1992. Ecology 2000: An essay on future directions in ecology. Bulletin of the Ecological Society of America 73: 165-170. 